\title{
Improvement of Pressing Technology of Products from Polytetrafluoroethylene
}

\author{
Dmitriy A. Negrov and Vitaly Yu. Putintsev* \\ Omsk State Technical University \\ Omsk, Russian Federation
}

Received 21.04.2021, received in revised form 25.07.2021, accepted 06.08.2021

\begin{abstract}
The development of new methods for obtaining materials with predetermined operational properties that ensure the durability and the wear resistance of friction units is an urgent problem in modern material science. The article considers the effect of ultrasonic pressing modes with simultaneously superimposed low-frequency amplitude modulation on the mechanical and tribotechnical properties of polytetrafluoroethylene. The comparison of the obtained research results of the new technology is carried out with the traditional pressing technology.

The results of studies indicated that the technology of ultrasonic pressing with the simultaneous application of low-frequency amplitude modulation makes it possible to increase the mechanical properties of PTFE: the tensile strength by $15 \%$, elongation by $13 \%$, the elastic modulus by $8 \%$, the hardness by $12 \%$, while the intensity of the mass wear rate is reduced by $40 \%$, and the coefficient of friction by $27 \%$.
\end{abstract}

Keywords: PTFE, ultrasonic action, low frequency modulation, intensity of the mass wear rate.

\section{Усовершенствование технологии прессования изделий}

\section{из политетрафторэтилена}

\author{
Д. А. Негров, В. Ю. Путинцев \\ Омский государственный технический университет \\ Российская Федерация, Омск
}

Аннотация. Разработка новых методов получения материалов с заранее заданными эксплуатационными свойствами, обеспечивающих долговечность и износостойкость узлов трения,

(C) Siberian Federal University. All rights reserved

This work is licensed under a Creative Commons Attribution-Non Commercial 4.0 International License (CC BY-NC 4.0).

* Corresponding author E-mail address: putintsev_vit@mail.ru 
является актуальной проблемой современной науки о материалах. В статье рассмотрено влияние режимов ультразвукового прессования с одновременно наложенной низкочастотной амплитудной модуляцией на механические и триботехнические свойства политетрафторэтилена. Проведено сравнение полученных результатов исследований новой технологии с традиционной технологией прессования. Показано, что технология ультразвукового прессования с одновременным наложением низкочастотной амплитудной модуляцией позволяет повысить механические свойства ПТФЭ: предел прочности при растяжении на $15 \%$, относительное удлинение на $13 \%$, модуль упругости на $8 \%$, твердость на $12 \%$, при этом интенсивность массового изнашивания снижается на $40 \%$, а коэффициент трения - на $27 \%$.

Ключевые слова: ПТФЭ, ультразвуковое воздействие, низкочастотная модуляция, интенсивность массового изнашивания.

Цитирование: Негров, Д.А. Усовершенствование технологии прессования изделий из политетрафторэтилена / Д.А. Негров, В. Ю. Путинцев // Журн. Сиб. федер. ун-та. Техника и технологии, 2021, 14(5). С. 564-571. DOI: 10.17516/1999-494X-0333

\section{Введение}

Развитие машиностроительного и нефтехимического производства неразрывно связано с применением новых материалов, к которым предъявляются все более высокие требования. Разработка новых методов получения материалов с заранее заданными эксплуатационными свойствами, обеспечивающих долговечность и износостойкость узлов трения, признана актуальной проблемой современной науки о материалах.

Полимерные материалы широко применяются в качестве материалов триботехнического назначения. Для изготовления деталей узлов трения (подшипники скольжения, подвижные вакуумные уплотнения, втулки, сальники) наиболее предпочтительным комплексом свойств обладает политетрафторэтилен (ПТФЭ) [1-3]. Уникальные антифрикционные свойства политетрафторэтилена, заключающиеся в низком коэффициенте трения между металлической поверхность и поверхностью фторопласта-4, существенно зависят от удельного давления, скорости скольжения, температуры, шероховатости поверхности. Известно, что низкие коэффициенты трения $(0,04-0,08)$ существуют только при скоростях скольжения менее $0,01 \mathrm{~m} / \mathrm{c}$, при увеличении скорости скольжения возрастает коэффициент трения ПТФЭ и составляет более $0,3[4-7]$.

Для наиболее эффективного решения данной проблемы необходимо применение новых технологических способов, которые бы позволили значительно повысить эксплуатационные свойства полимеров и тем самым расширить область их применения в производстве. Традиционной технологией, используемой при производстве изделий из полимерных материалов, является прессование из порошка заготовок и их последующее спекание.

На сегодняшний день существуют различные способы повышения механических и триботехнических свойств полимерных материалов, такие как введение модификаторов в полимерную матрицу, изменение режимов технологических операций (измельчение, прессование, термообработка), наложение внешнего энергетического воздействия на прессуемый материал, которые позволяют частично решить эту проблему [8-11].

Целью данной работы является повышение механических и триботехнических свойств ПТФЭ за счет введения ультразвуковых колебаний с одновременно наложенной низкочастотной амплитудной модуляцией.

$$
-565-
$$




\section{Объекты и методы исследования}

Объектом исследования служит политетрафторэтилен марки ПН-20 плотностью 2,16 г/ $\mathrm{cm}^{3}$, средний размер частиц 6-20 мкм.

Методика исследования заключалась в определении влияния технологических параметров ультразвукового прессования с наложением низкочастотной модуляции (частота низкочастотной модуляции, давление прессования, время) на механические и триботехнические свойства полимерного материала.

Образцы для проведения исследований изготовлены по технологии холодного прессования. Предварительно проведено размельчение порошка в лабораторной мельнице с частотой вращения ножей не менее 2800 мин $^{-1}$.

Для сравнения механических и триботехнических свойств были изготовлены образцы по трем технологическим режимам:

При первом режиме проводится традиционное прессование без внешнего энергетического воздействия (без УЗ). Второй режим заключается в воздействие ультразвуковых колебаний 17000 Гц с одновременно наложенной низкочастотной модуляцией 100 Гц (У3+100). Третий режим - ультразвуковые колебания 17000 Гц с одновременно наложенной низкочастотной модуляцией 500 Гц (УЗ+500). Время прессования составляло 30, 60 и 90 с.

Образцы для исследований изготавливали на установке, состоящей из гидравлического пресса ГМС-50, модернизированного ультразвукового генератора УЗГ-6М, работающего в частотном диапазоне 17-23 кГц, магнитострикционного преобразователя ПМС-15А-18.

Термическая обработка материалов проводилась в программируемой печи СНОЛ 7/10. Режим спекания образцов ПТФЭ заключался в плавном нагреве до $(360 \pm 1){ }^{\circ} \mathrm{C}$ в течение 70 мин, выдержке заготовки при температуре $(360 \pm 1){ }^{\circ} \mathrm{C}$ в течение 60 мин, регулируемом охлаждении со скоростью $0,5^{\circ} \mathrm{C} /$ мин до $327^{\circ} \mathrm{C}$ и последующем охлаждении вместе с печью до комнатной температуры.

Для определения механических свойств согласно ГОСТ 11262-80 использовалась машина для испытаний Zwick Roell BT2. Модуль упругости определялся по стандартной методике ГОСТ 25.601-80. Твердость материала определялась по Шору с помощью твердомера TBP-D (шкала D).

Определение триботехнических характеристик проводилось на машине трения УМТ-2168. Диаметр образцов 10,0 \pm 0,1 мм, длина $15 \pm 0,1$ мм, контртело - стальной диск из стали марки 45 с твердостью 45-50 HRC, шероховатостью Ra $<0,32$ мкм. При проведении испытаний к образцам прикладывалась нормальная нагрузка $-471 \mathrm{H}$, линейная скорость скольжения составляла 0,75 м/с, время испытания 60 мин.

\section{Результаты исследований и обсуждения}

В результате проведенных исследований установлено, что у образцов, отпрессованных при давлении 80 МПа с ультразвуковым воздействием и низкочастотной модуляцией 100 Гц, достигается максимальное значение предела прочности 32 МПа, что на 15 \% больше, чем у образцов, отпрессованных по традиционной технологии (рис $1 b$ ). Увеличение давления прессования до 90 МПа приводит к уменьшению предела прочности для всех технологических режимов. 
Максимальное значение относительного удлинения достигается также на режиме У3+100 и составляет 500 \% при давлении прессования 80 МПа, дальнейшее увеличение давления прессования не приводит к изменению относительного удлинения (рис. $2 b$ ). Относительное удлинение у образцов УЗ+100 на 13 \% выше, чем без ультразвукового воздействия. На других режимах прессования при давлении более 80 МПа значения относительного удлинения резко уменьшаются (рис. $2 a, c)$.

Модуль упругости у всех образцов, представленных на рис. 3, носит ярко выраженный экстремальный характер с максимумом при давлении прессования 80 МПа. Максимальный показатель модуля упругости достигается на режиме УЗ+100 и составляет $421 \mathrm{MПа} \mathrm{-} \mathrm{это} \mathrm{на} 8$ \% больше, чем у образцов, изготовленных по традиционной технологии.

Определено оптимальное время прессования 60 с при давлении 80 МПа. Дальнейшее увеличение времени прессования не приводит к изменению значений модуля упругости (рис. 4).

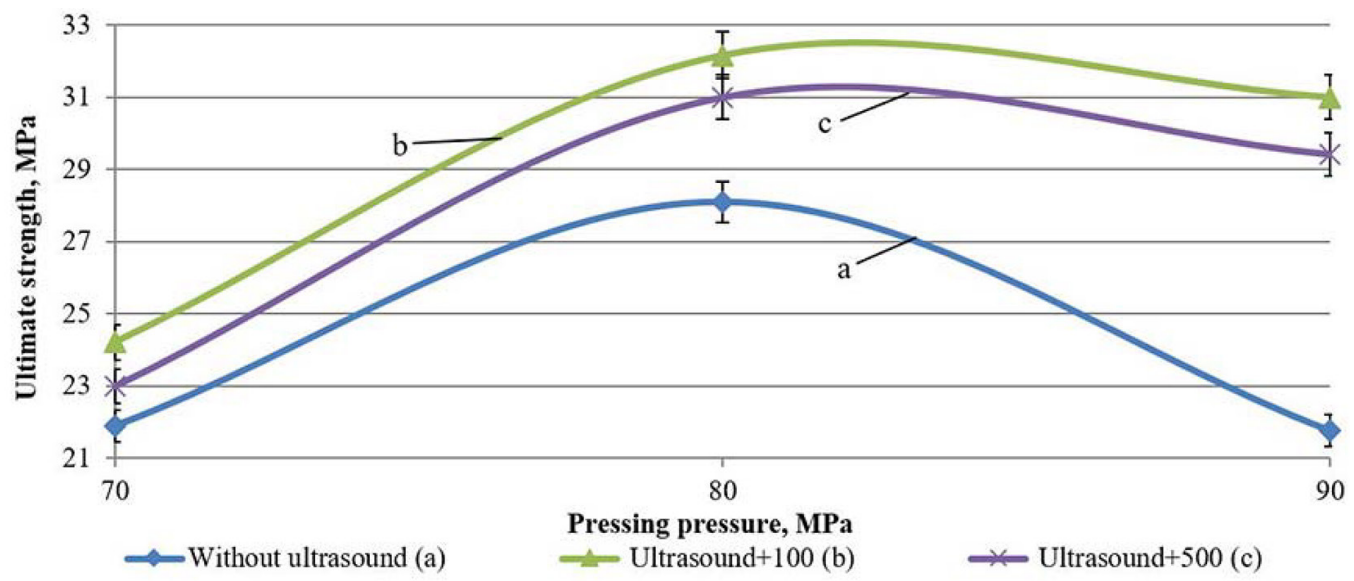

Рис. 1. Зависимость предела прочности от давления прессования

Fig. 1. Dependence of ultimate strength on pressing pressure

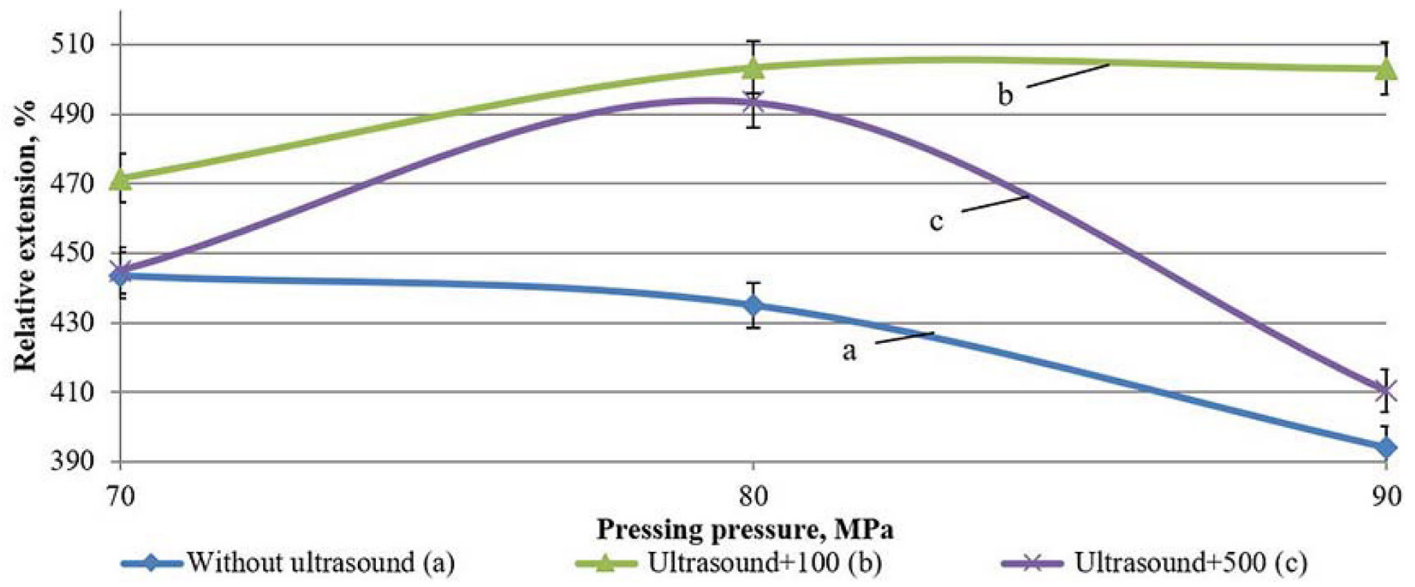

Рис. 2. Зависимость относительного удлинения от давления прессования

Fig. 2. Dependence of the relative elongation on the pressing pressure

$$
-567-
$$




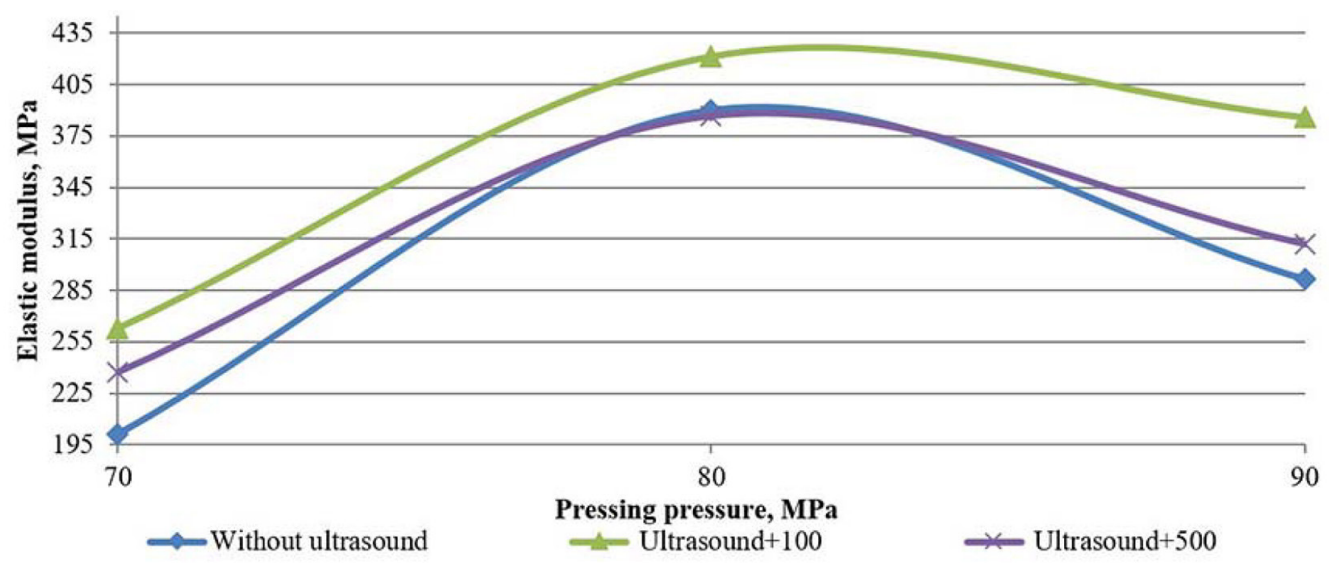

Рис. 3. Зависимость модуля упругости от давления прессования

Fig. 3. Dependence of the modulus of elasticity on the pressing pressure

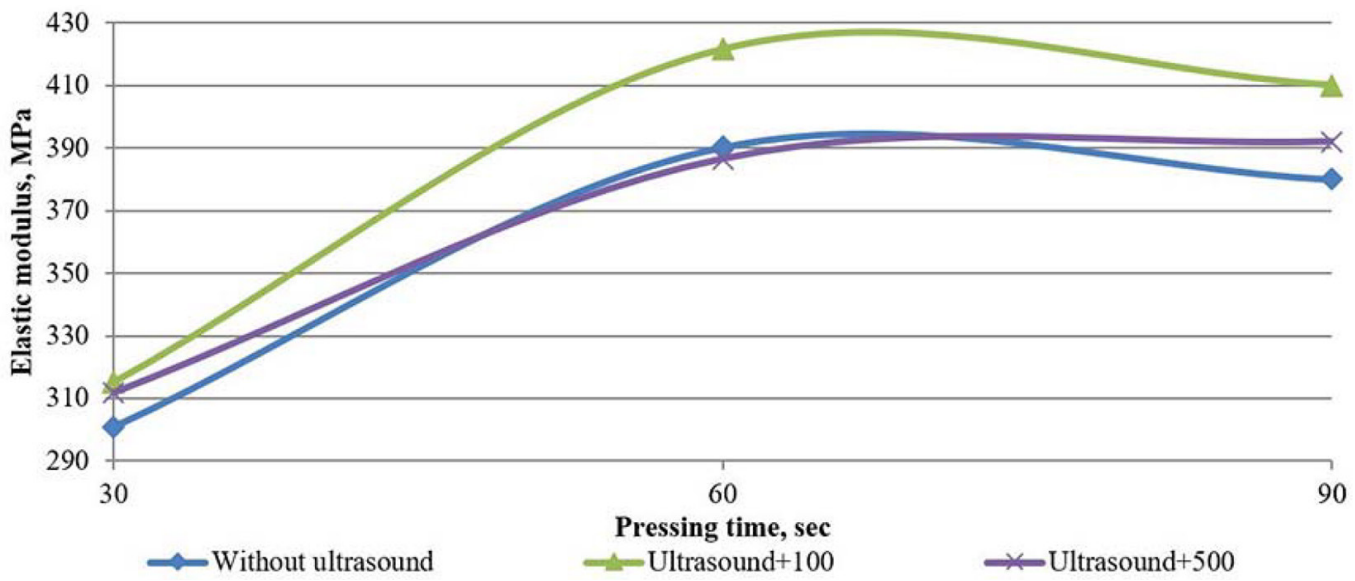

Рис. 4. Зависимость модуля упругости от времени прессования

Fig. 4. Dependence of the modulus of elasticity on the pressing time

Исследование твердости полученных образцов (рис. 5) показывает, что при давлении прессования 80 МПа на режимах УЗ+100 и УЗ+500 твердость составляет 59-60 единиц, что на 12 \% больше, чем у образцов, полученных прессованием без ультразвукового воздействия. Дальнейшее увеличение давления прессования не сказывается на изменения твердости материала.

На основании вышеизложенных результатов исследований механических свойств установлено, что применение ультразвукового прессования с наложением низкочастотной модуляции 100 Гц в технологии производства изделий из ПТФЭ (время прессования 60 с, давление прессования 80 МПа) позволяет повысить предел прочности на $15 \%$, относительное удлинение - на $13 \%$, модуль упругости - на $8 \%$, твердости - на $12 \%$.

Анализ триботехнических свойств материала показал, что минимальная интенсивность массового изнашивания достигается на режиме УЗ+100 при давлении 80 МПа и составляет 0,394 г/ч, что на 40 \% меньше чем у образцов, полученных по традиционной технологии (рис. 6). 


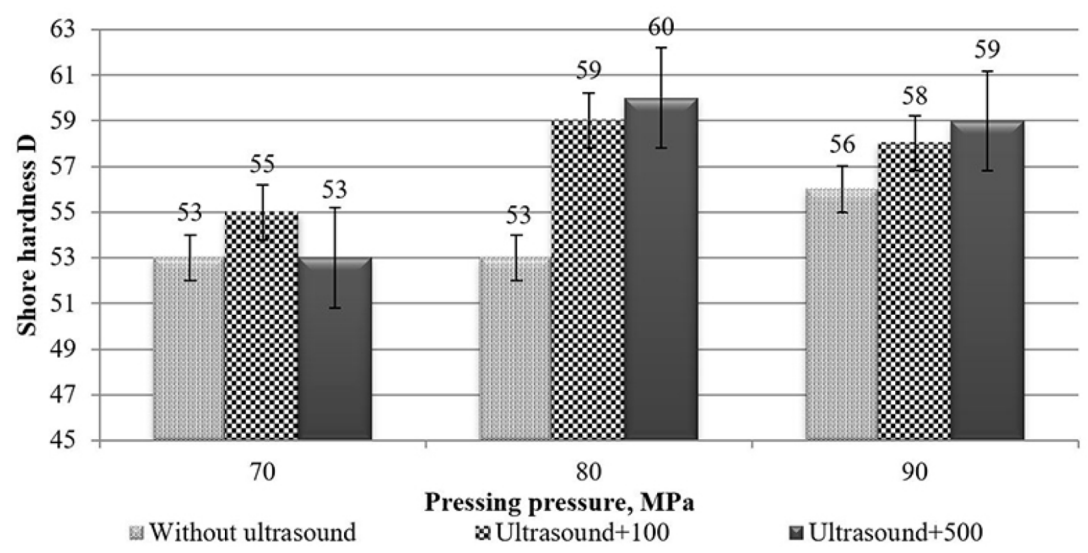

Рис. 5. Зависимость твердости по Шору (D) от давления прессования

Fig. 5. Dependence of Shore hardness (D) on the pressing pressure

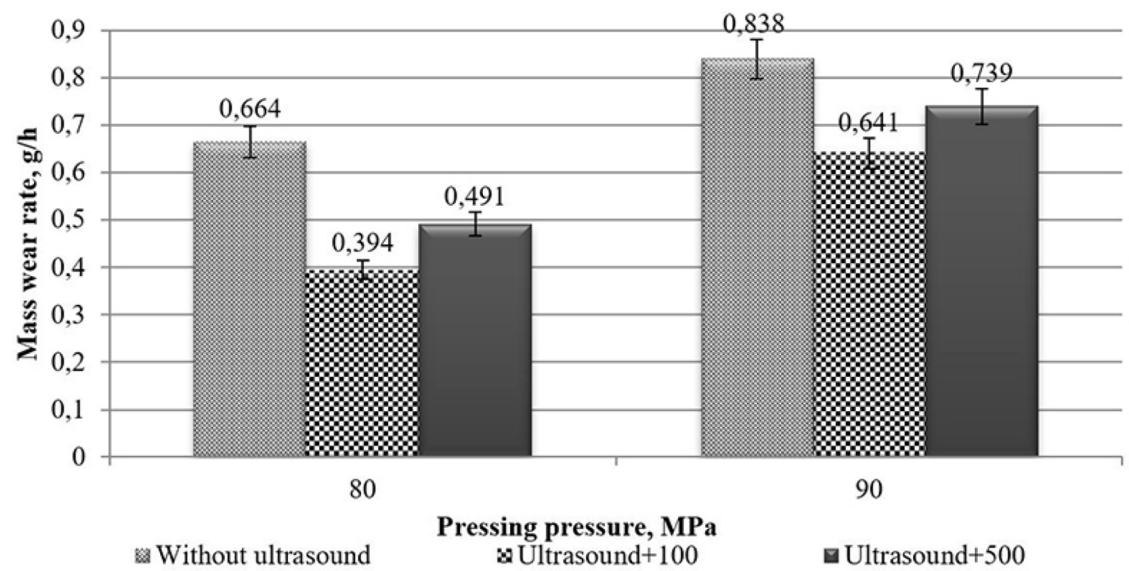

Рис. 6. Зависимость интенсивности массового изнашивания от давления прессования

Fig. 6. Dependence of the intensity of mass wear on the pressing pressure

Значение коэффициента трения при этом составляет 0,266, что на 27 \% меньше по сравнению с режимом без внешнего энергетического воздействия (рис. 7).

Повышение износостойкости на этапе прессования за счет режима ультразвукового воздействия с одновременно наложенной низкочастотной модуляцией, возможно, связано с изменением надмолекулярной структуры, усилением межмолекулярного когезионного взаимодействия частиц порошка, уменьшением пор за счет наложения акустических волн разной частоты. 


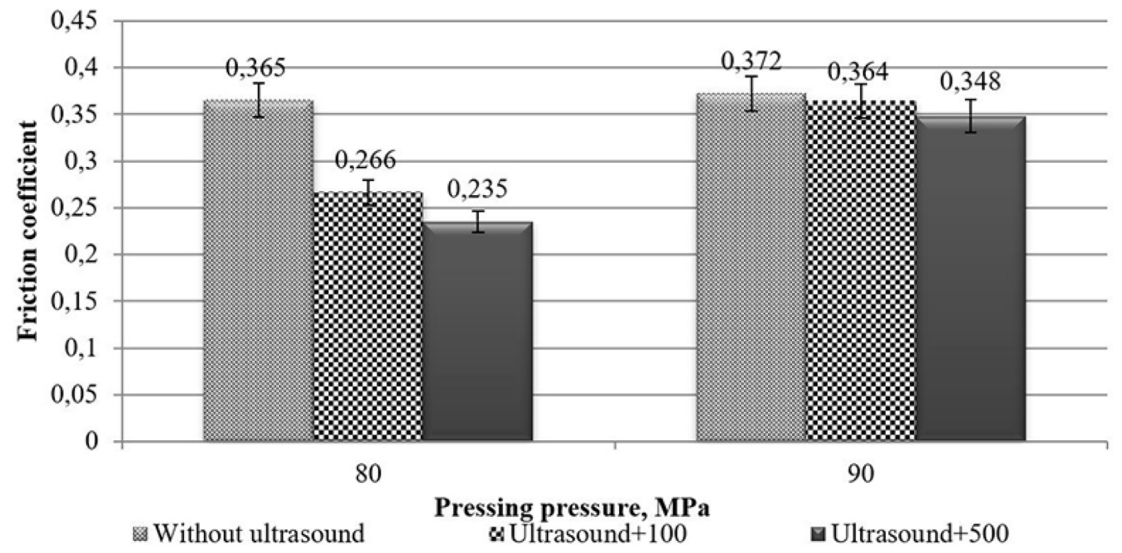

Рис. 7. Зависимость коэффициента трения от давления прессования

Fig. 7. Dependence of the coefficient of friction on the pressing pressure

\section{Вывод}

На основании проведенных исследований разработан технологический режим прессования ПТФЭ с применением ультразвукового воздействия частотой 17 кГц и одновременно наложенной низкочастотной амплитудной модуляцией 100 Гц (время прессования 60 с, давление прессования 80 МПа).

Данный режим позволяет повысить механические свойства ПТФЭ: предел прочности при растяжении на $15 \%$, относительное удлинение на $13 \%$, модуль упругости на $8 \%$, твердость на $12 \%$, при этом интенсивность массового изнашивания снижается на $40 \%$, а коэффициент трения - на $27 \%$.

Разработанная технология ультразвукового прессования будет применяться на предприятии НТК «Криогенная техника» при производстве подвижных вакуумных уплотнений.

\section{Благодарность / Acknowledgement}

Исследование выполнено при финансовой поддержке РФФИ в рамках научного проекта № 20-33-90109.

The study was carried out with the financial support of the Russian Foundation for Basic Research in scientific project No. 20-33-90109.

\section{Список литературы / References}

[1] Охлопкова А.А., Петрова П.Н., Попов С.Н., Слепцова С.А. Полимерные композиционные материалы триботехнического назначения на основе политетрафторэтилена. Российский химический журнал, 2008, 3, 147-152 [Okhlopkova A.A., Petrova P.N., Popov S. N., Sleptsova S. A. Polymer composite materials for tribotechnical purposes based on polytetrafluoroethylene. Russian Chemical Journal, 2008, 3, 147-152 (in Russian)].

[2] Negrov D. A., Eremin E. N. Manufacture of slip bearings from PTFE-based composite Russian Engineering Research, 2012, 32(1), 42-44.

[3] Негров Д.А., Путинцев В.Ю., Передельская О.А., Наумова А.В. Технология изготовления деталей узлов трения из полимерных композиционных материалов. Вестник Южно- 
Уральского государственного университета. Серия: Машиностроение, 2015, 15(2), 13-19 [Negrov D. A., Putintsev V. Yu., Peredelskaya O. A., Naumova A. V. Manufacturing technology of friction unit parts from polymer composite materials. Bulletin of the South Ural State University. Series: Mechanical Engineering, 2015, 15(2), 13-19 (in Russian)]

[4] Wang J., Yan F., Xue Q. Tribological behavior of PTFE sliding against steel in sea water. Wear, 2009, 267(9-10), 1634-1641.

[5] Alam K.I., Dorazio A., Burris D.L. Polymers tribology exposed: eliminating transfer film effects to clarify ultralow wear of PTFE. Tribology Letters, 2020, 68, 1-13.

[6] Conte M., Fernandez B., Igartua A. Effect of surface temperature on tribological behavior of PTFE composites. Proceedings of the Surface Effects and Contact Mechanics X. UK, 2011, 1, 219-230.

[7] Панин С.В., Корниенко Л.А., Нгуен С., Иванова Л.Р., Корчагин М.А., Шилько С. В., Плескачевский Ю.М. Износостойкость композитов на гибридной матрице СВМПЭ-ПТФЭ: механические и триботехнические свойства. Трение и износ, 2015, 36(3), 325-333 [Panin S. V., Kornienko L. A., Nguyen S., Ivanova L. R., Korchagin M. A., Shilko S. V., Pleskachevsky Yu. M. Wear resistance of composites based on a hybrid UHMWPE-PTFE matrix: mechanical and tribotechnical properties. Friction and Wear, 2015, 36 (3), 325-333 (in Russian)].

[8] Кропотин О.В., Машков Ю. К., Кургузова О.А. Создание полимерного антифрикционного нанокомпозита на основе политетрафторэтилена с повышенной износостойкостью. Омский научный вестник, 2013, 120(2), 86-90 [Kropotin O.V., Mashkov Yu.K., Kurguzova O. A. Creation of an antifriction polymer nanocomposite based on polytetrafluoroethylene with increased wear resistance. Omsk Scientific Bulletin, 2013, 120 (2), 86-90 (in Russian)].

[9] Воропаев В.В., Струк В. А., Горбацевич Г.Н., Лавринюк И. Л. Технология высокопрочных композиционных материалов на основе модифицированного политетрафторэтилена. Известия наииональной академии наук Беларуси. Серия физико-технических наук, 2012, 3, 31-38 [Voropaev V.V., Struk V.A., Gorbatsevich G. N., Lavrinyuk I. L. Technology of high-strength composite materials based on modified polytetrafluoroethylene. Bulletin of the National Academy of Sciences of Belarus. Series of Physical and Technical Sciences, 2012, 3, 31-38 (in Russian)].

[10] Макаров М.М., Слепцова С.А., Москвитина Л.В., Капитонова Ю.В. Влияние технологии совмещения на свойства полимерных композитов на основе политетрафторэтилена и флогопита. Вестник СВФУ, 2016, 52(2), 76-86 [Makarov M.M., Sleptsova S. A., Moskvitina L. V., Kapitonova $\mathrm{Yu}$. V. Influence of the alignment technology on the properties of polymer composites based on polytetrafluoroethylene and phlogopite. Bulletin of NEFU, 2016, 52 (2), 76-86 (in Russian)].

[11] Негров Д.А., Еремин Е.Н., Путинцев В.Ю., Передельская О. А., Андреева С. А. Влияние ультразвукового воздействия на механические свойства политетрафторэтилена, модифицированного детонационными наноалмазами. Омский научный вестник, 2014, 130(2), 7679 [Negrov D. A., Eremin E.N., Putintsev V. Yu., Peredelskaya O.A., Andreeva S. A. Influence of ultrasonic action on the mechanical properties of polytetrafluoroethylene modified with detonation nanodiamonds. Omsk Scientific Bulletin, 2014, 130 (2), 76-79 (in Russian)]. 